\title{
THE RELATIONSHIP BETWEEN GASTRIC SECRETORY INHIBITION AND CEREBRAL AND GASTRIC LEVELS OF MONOAMINES IN PYLORUS-LIGATED RATS
}

\author{
Isamu YAMAGUCHI, Shoji KATSUKI, Takeo OHASHI \\ and Shigenobu KUMADA \\ Research Laboratory, Fuiisawa Pharmaceutical Co., Ltd, \\ Higashiyodogawa-ku, Osaka, Japan
}

Accepted February 2, 1973

\begin{abstract}
Neuroleptics, antidepressants and minor tranquilizers were compared quantitatively for the effects on gastric secretion in Shay rats and on barbiturate sleep in mice. In this experiment, it was shown that these two actions of neuroleptics are clcarly related and it is suggested that there may be some relationship between these two actions themselves regarding neuroleptics. The antisecretory action of neuroleptics and antidepressants, mentioned above, was reduced in rats pretrcated with reserpine. The gastric secretion in Shay rats was clearly enhanced following a single injection of reserpine. This enhanced secretory volume and reduced antisecretory activity of chlorpromazine after reserpine returned to the control concomitantly with the recovery of the cerebral levels of norepinephrine and serotonin and gastric levels of norepinephrine. Antisecretory activity of imipramine and gastric levels of serotonin revealed a more rapid recovery after rcserpine treatment. Furthermore, reserpine analogues and p-chlorophenylalanine were studied for the effects on the secretory volume and the antisecretory activity of chlorpromazine in Shay rats and on monoamine contents. It is postulated that the cerebral rather than gastric norepinephrine plays an inhibitory role in gastric secretion in Shay rats and is presumably involved in the antisecretory effect of chlorpromazine, and also possibly that of neuroleptics and antidepressants.
\end{abstract}

Pylorus ligation procedure in rats, which was developed by Shay et al. (1) for the production of perforating gastric ulceration, has usually been used in the study of gastric secretion (2-4). Brodic (3) proposed that the vago-vagal reflex has an effect on the acidity in the pylorus-ligaled rats, and showed that vagotomy abolished gastric secretion in pyloruslisited rats.

Komarov et al. (5) demonstrated that there was a clear relationship between gastric secretion and central activity in chronic fistula rats. In these animals, the amygdala (6) and hypothalamus $(7,8)$ regulated the gastric secretion, and in pylorus-ligated rats, drugs depressing the central nervous system inhibited the gastric secretion (4). Lee et al. (6) stated that acetylcholine is a stimulatory transmitter, while serotonin is an inhibitory transmitter in the amygdaloid area. A series of drugs prolonging the half-life of catecholamine either in the brain or in the stomach were shown to be antisecretory (4). On the contrary, reserpine, a monoamine depletor, produced secretory stimulation (9-11). Thus it can be speculated that cerebral or gastric monoamine are the contributing factors to 
the vagal tone and that they may play some no in gastric secretory inhibition.

The present study was undertaken to investigate $l$ ) the relationship between the gastric secretory inhibition and the depression of central nervous system by central depressant, and 2) the role of monoamines in the secretory inhibition induced by drugs.

\section{MATERIALS AND METHODS}

\section{Shay rats}

Wistar strain male rats weighing 100 to $150 \mathrm{~g}$ were fasted for $24 \mathrm{hr}$ before the operation. During the fasting periods, water was permitted. Under light ether anesthesia, the pylorus was ligated according to the method described by Shay et al. (1). Immediately after the operation, the test drugs were administered s.c., and 4 hr later the animals were sacrificed under chloroform inhalation. The stomach was removed and the volume of gastric juice was determined. The volume of gastric juice was expressed as $\mathrm{m} / 100 \mathrm{~g}$ bw. Each group of animals received one dose of the test drugs. The control groups were given only the vehicle. The mean value in the test group was compared to that in the control. The inhibitory percentage of gastric secretion was plotted against each dose on semilogarithmic paper and the value representing a $50 \%$ reduction $\left(E D_{50}\right.$ ) was read on the graph.

2. Prolongation of the barbiturate sleeping time

Mice (d-d strain) weighing $1525 \mathrm{~g}$ were used. Methyihexabital-Na $(90 \mathrm{mg} / \mathrm{kg}$ ) was injected i.p. and sleeping time, the period between the loss and the recovery of righting reflex, was measured. Test drugs were given s.c. 30 min prior to an injection of methylhexabital-Na. The prolongation percent of sleeping time in cach dose was determined for the control of each group. The prolongation percent was plotted against the dose of the test drugs on semilogarithmic paper, and $100 \%$ prolongation dose $\left(\mathrm{PD}_{100}\right)$ was read on the graph.

\section{Chemical assay of norepinephine and serotonin}

Brains and stomachs were removed from male Wistar rats $(100-150 \mathrm{~g})$ which had been sacrificed under chloroform inhalation. These were homogenized with 20 vol. of acidified $n$-butanol by the method described by Mead and Finger (12). The acid homogenate was transfered to a centrifuge tube containing excess of $\mathrm{NaCl}$, and then centrifuged at $2500 \mathrm{rpm}$ for $10 \mathrm{~min}$. An aliquot of organic phase taken from the acid homogenate was used for the subsequent procedures.

One aliquot of butanol extract was shaken with $0.02 \mathrm{~N} \mathrm{HCl}$ and an equal volume of n-heptane, and the aqueous phase was determined for norepinephrine by the trihydroxyindole method (13).

Another aliquot of butanol extract, washed twice with borate buffer (pH 10), was mixed with $0.1 \mathrm{~N} \mathrm{HCl}$ and an equal volume of n-heptane by shaking. An aqueous phase of this mixure was determined for serotonin by its native fluoreseence (14).

4. Drugs

Drugs used were as follows; chlorprothixene; ocloclothepine (Forschungsinstitute 
für Pharmazie und Biochiemi, Prag); perphenazine; levomepromazine; chlorpromazine; haloperidol; molindone (Endo Labs. Inc.); desipramine; amitryptyline; imipramine; prazepam; chlordiazepoxide; pentolinium bitartrate; atropine sulfate; reserpine; tetrabenazine; bictaserpine; DL-p-chlorophenylalanine.

\section{RESULTS}

\section{Effect of drugs on gastric secretion in Shay rats}

Each day, 20 animals were used and divided into 4 groups of 5 . One served as the control group, the others as test groups. This experimental schedule was repeated. The mcan secretory volume of a control group varied day by day, ranging from 2.13 to 5.19 $\mathrm{ml} / 100 \mathrm{~g}$. The mean value of all control animals $(\mathrm{n}=254)$ was $4.11+0.08 \mathrm{ml} / 100 \mathrm{~g}$ (mean + S.E.). The $50 \%$ inhibiting doses $\left(E_{50}\right)$ of gastric secretion of the centrally acting drugs used in this experiment are shown in Table 1.

TABLL 1. Effect of centrally acting drugs on gastric secretion in Shay rats and on barbiturate sleeping time in mice.

\begin{tabular}{lcccc}
\hline \multicolumn{1}{c}{ Drug } & $\begin{array}{c}\text { Route of } \\
\text { administration }\end{array}$ & $\begin{array}{c}\mathrm{PD}_{100^{*}} \\
\mathrm{mg} / \mathrm{kg}\end{array}$ & $\begin{array}{c}\mathrm{ED}_{50} \mathrm{mg} / \mathrm{kg}^{* *} \\
\text { Reserpinized } \\
\text { rats*** }\end{array}$ \\
Chlorprothixene & s.c. & 0.33 & 0.46 & $>4$ \\
Octoclothepine & s.c. & 0.41 & 0.50 & $>4$ \\
Perphenazine & s.c. & 3.15 & 1.1 & $>8$ \\
Leyomepromazine & s.c. & 0.26 & 1.3 & $>8$ \\
Chlorpromazine & s.c. & 1.2 & 2.0 & $>32$ \\
Haloperidol & s.c. & 3.4 & 2.8 & $>16$ \\
Molindone & s.c. & 52 & 41 & $>125$ \\
Desipramine & s.c. & 15 & 4.6 & 12 \\
Amitriptyline & s.c. & 9.0 & 8.6 & 34 \\
Imipramine & s.c. & 18 & 14 & 46 \\
Prazepam & s.c. & 2.8 & 115 & \\
Diazepam & s.c. & 1.4 & $>250$ & \\
Chlordiazepoxide & s.c. & 12 & $>250$ & \\
\hline
\end{tabular}

* dose which prolongs barbiturate sleep by $100 \%$.

** dose which inhibits gastric secretion by $50 \%$.

At least 4 groups of 5 animals were used to determine the doses shown above.

*** rats were pretreated with reserpine $(5 \mathrm{mg} / \mathrm{kg}$ s.c.) $24 \mathrm{hr}$ before the test.

The tricyclic ncuroleptics, phenothiazincs, chlorprothixene and octoclothepine, had the most potent antisecretory activity in centrally acting drugs, neuroleptics, antidepressants and minor tranquilizers. The $E_{50}$ values of those drugs ranged from 0.46 to 2.0 $\mathrm{mg} / \mathrm{kg}$. The butyrophenone, haloperidol, was slightly less active than tricyclic neuroleptics. The $E D_{50}$ values of antidepressants, desipramine, amitriptyline and imipramine were $4.6,8.6$ and $14 \mathrm{mg} / \mathrm{kg}$, respectively. Molindone inhibited gastric secretion only at a rather large dose.

On the other hand, minor tranquilizers, i.e. benzodiazepine compounds were very 
weak in the activity required to inhibit the gastric secretion. Benzodiazepine compounds, chlordiazepoxide, diazepam and prazepam, inhibited the gastric secretion only at a dose larger than $100 \mathrm{mg} / \mathrm{kg}$.

It was confirmed that atropine and pentolinium were the strong secretory antgonists in Shay rats. The $E D_{50}$ values of atropine and pentolinium were 0.16 and $2.3 \mathrm{mg} / \mathrm{kg}$, respectively. Bilateral vagotomy at the neck induced a $78 \%$ decrease in the secretory volume.

\section{Effect of the drugs on methylhexabital sleeping time in mice}

Forty animals were used and divided into 4 groups of 10 . One served as the control group the others as test groups. This experimental schecule was repeated. The mean sleeping time of a control group was approx. $20 \mathrm{~min}$, ranging from 15 to $30 \mathrm{~min}$. The $100 \%$ prolongating doses of barbiturate slceping time $\left(\mathrm{PD}_{100}\right)$ of drugs are shown in Table 1.

Centrally acting drugs all prolonged barbiturate sleeping time in mice, and have been arranged in order of decreasing potency in this respect; tricyclic neuroleptics, butyrophenones, benzodiazepines, antidepressants and molindone.

Except for benzodiazepines, the order of potency of the centrally acting drugs to prolong the barbiturate sleeping time was almost the same as that required to inhibit gastric secretion. The $\mathrm{PD}_{100}$ values of these drugs were about equal to their corresponding $\mathrm{ED}_{50}$ values in Shay rats. Concerning neuroleptics, the correlation between the inhibition of gastric secretion in Shay rats and the prolongation of barbiturate sleeping time in mice is illustrated in Fig. 1 where the PD $_{1 v 0}$ in the prolongation of barbiturate sleep is plotted against the $\mathrm{ED}_{50}$ in Shay rats. The regression line was highly significant, and the $\mathrm{ED}_{50}$ in Shay rats and the $\mathrm{PD}_{100}$ in barbiturate sleep were positively correlated with a high cor-

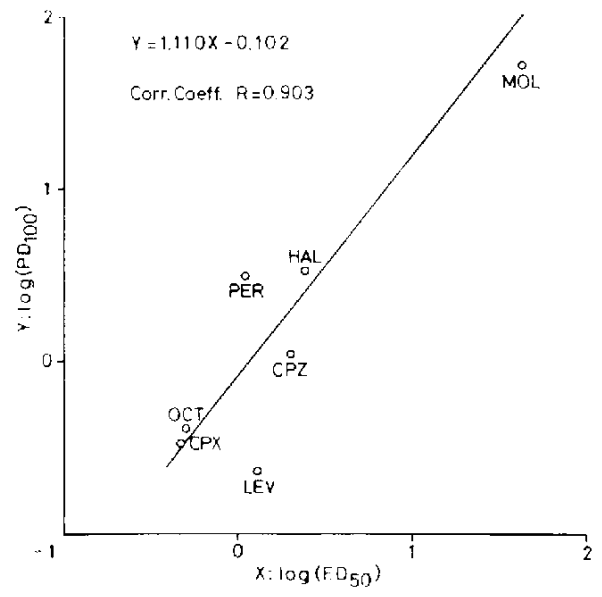

FIG. 1. Relationship between $100 \%$ prolonging dose of barbiturate sleep in mice $\left(\mathrm{PD}_{100}\right)$ and $50 \%$ inhibiting dose of gastric secretion in Shay rats $\left(\mathrm{ED}_{50}\right)$ of neuroleptics. CPX : chlorprothixene, OCT : octoclothepine, LEV : levomepromazine, PER : perphenazine, CPZ : chlorpromazine, HAL : haloperidol, MOL : molindone. 
relation coefficient $(\mathrm{r}=0.903)$.

On the other hand, no direct correlation was noted between these two actions of minor tranquilizers, i.e. benzodiazepine compounds. Benzodiazepine compounds, chlordiazepoxide, diazepam and prazepam, markedly prolonged the barbiturate sleep at a dose of 1-12 mg/kg. The potencies were comparable to that of butyrophenone, while these drugs inhibited gastric secretion only at dose larger than $100 \mathrm{mg} / \mathrm{kg}$ and were about onefiftieth to one-onehundredth less effective in inhibiting gastric secretion than in potentiating barbiturate sleep.

\section{Effect of drugs on gastric secretion in Shay rats treated with reserpine}

Neuroleptics and antidepressants inhibited gastric secretion in Shay rats (4) and gastric hemorrhage induced by cold and restraint stress (15). Antidepressants, but not neuroleptics, inhibited gastric hemorrhage induced by reserpine (16). It is well known that gastric secretion and gastric hemorrhage are related to the vagal activity $(3,9,15)$. These results suggest that neuroleptics and antidepressants decreased the vagal tone through different mechanisms. Thus we investigated the antisecretory effect of neuroleptics and anti-depressants in Shay rats treated with reserpine.

Twenty-four hr prior to pylorus ligation, rats were administered s.c. $5 \mathrm{mg} / \mathrm{kg}$ of reserpine. The subsequent experimental schedule was the same as in normal Shay rats described previously. The mean secretory volume of a control group varied day by day, ranging from 2.68 to $6.36 \mathrm{ml} / 100 \mathrm{~g}$. The mean value of all control animals $(\mathrm{n}=100)$ was $5.10 \pm 0.14 \mathrm{ml} / 100 \mathrm{~g}$ (mean $t_{-} S . E$.). The $E D_{50}$ values of the drugs are shown in Table 1 .

In the reserpine treated Shay rats, the antisecretory activities of the neuroleptics and the antidepressants were markcdly reduced or abolished. Tricyclic neuroleptics did not reduce the volume of gastric juice even at ten times the effective dose in normal Shay rats. Molindone and antidepressants were roughly one-half to one-fifth less effective in reserpine treated Shay rats than in normal Shay rats.

The $\mathrm{ED}_{50}$ values of pentolinium and atropine were 2.3 and $0.16 \mathrm{mg} / \mathrm{kg}$ in normal Shay rats, and 2.9 and $0.09 \mathrm{mg} / \mathrm{kg}$ in reserpine treated Shay rats. Bilateral vagotomy at the neck caused $85 \%$ decrease in secretory volume in reserpine treated Shay rats. These drugs caused almost equal inhibitory activity on gastric secretion both in normal and reserpine treated Shay rats.

4. Time-course of antisectetory activities of chlorpromazine and imipramine in reserpine treated Shay rats

Chlorpromazine ( $4 \mathrm{mg} / \mathrm{kg}$ s.c.) and imipranine $(32 \mathrm{mg} / \mathrm{kg}$ s.c.) reduced the volume of gastric juice by 68.5 and $72.8 \%$ in normal Shay rats, respectively. The antisecretory activities of these drugs were determined at 1,2, 4, 8, 16 and 24 days after reserpine (5 $\mathrm{mg} / \mathrm{kg}$ s.c.). Results are shown in Fig. 2. The antisecretory activities of these drugs in normal Shay rats had served as the control value.

The antisecretory activities of these drugs decreased markedly $24 \mathrm{hr}$ after reserpine and were one-half to one-third as efiective as in normal Shay rats. Thereafter the 


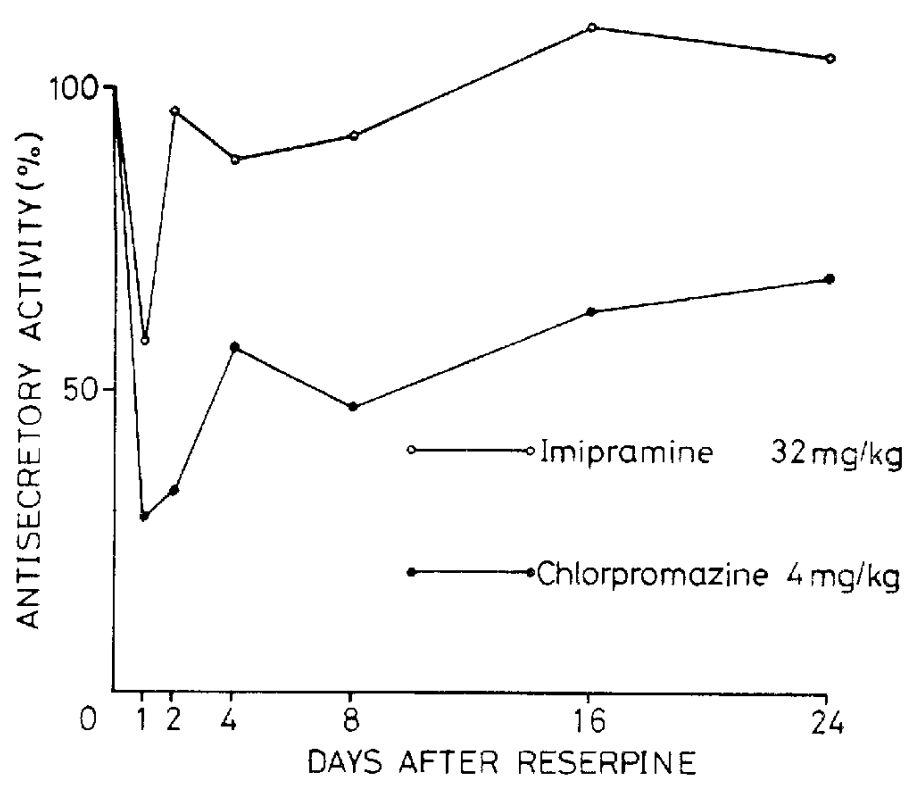

FIG. 2. Antisecretory activity of chlorpromazine and imipramine in reserpine treated Shay rats. Each point represents the mean of at least 10 animals.

decreased antisecretory activity progressively recovered. Twenty-four days after reserpine the gastric inhibitory activities of these drugs were 69.3 and $106.0 \%$ of the control, respectively.

The time-course of the activity differed somewhat. The antiscerctory activily of imipramine recovered very rapidly. Two days after reserpine, the activity of imipramine was comparable to that in normal Shay rats. The recovery of antisecretory activity of chlorpromazine was more gradual and delayed than that of imipramine.

5. Time-course of the secretory volume in Shay rats following reserpinc

Rats were divided into three groups, and $0.9 \%$ saline and reserpine 2.5 and $5 \mathrm{mg} / \mathrm{kg}$ were injected respectively. Tests for gastric secretion were done at $1,2,4,8,16$ and 24 days thereafter. Time-course of the secretory volume following reserpine is illustrated in Fig. 3.

Secretory volume of the control groups ranged from 2.1 to $3.4 \mathrm{ml} / 100 \mathrm{~g}$. In animals on 2.5 and $5 \mathrm{mg} / \mathrm{kg}$ of reserpine, the vol. of gastric juice ranged from $3.4105 .4 \mathrm{ml} / 100 \mathrm{~g}$ within 8 days after reserpine. On the other hand, the vol. of gastric juice wilhin 8 days after reserpine was apparently greater than that of the control. The secretory enhancement by reserpine declined progressively. 'Iwenty-four days after reserpine, the volume of gastric juice was approx. equal to that of the control.

In reserpine treated Shay rats, time-course of the secretory volume increase coincided with that of the decrease in antisecretory activity of chlorpromazine.

6. Time-course of monoamine levels in the brain and stomach after reserpine

Cerebral and gastric levels of norepinephrine and serotonin were determined 1, 2, 


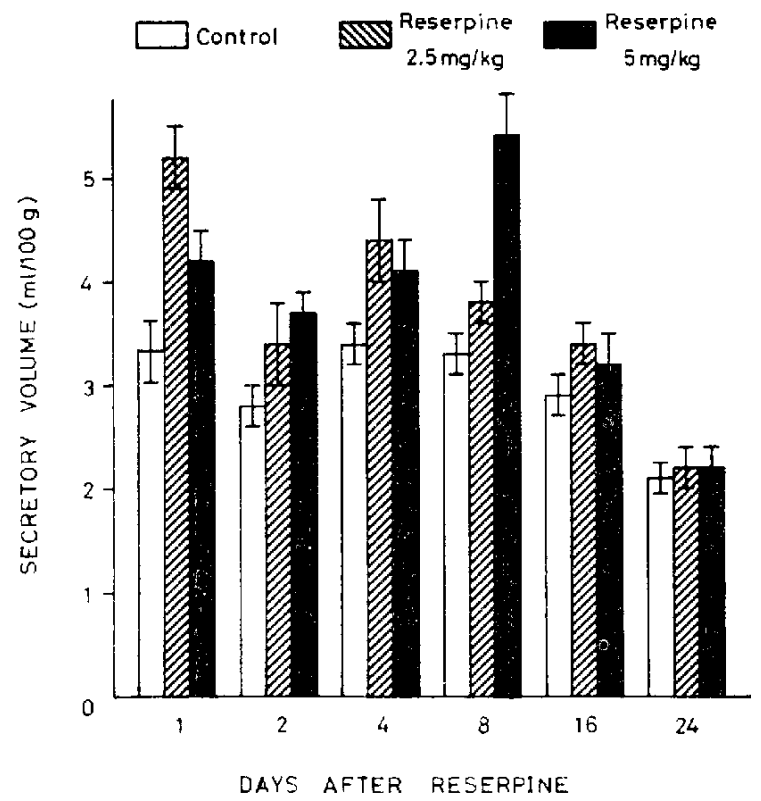

FIG. 3. Volume of gastric juice in Shay rats treated with 2.5 and $5 \mathrm{mg} / \mathrm{kg}$ of reserpine. Each value is the mean of at least 15 animals. Vertical lines represent standard errors of the mean.

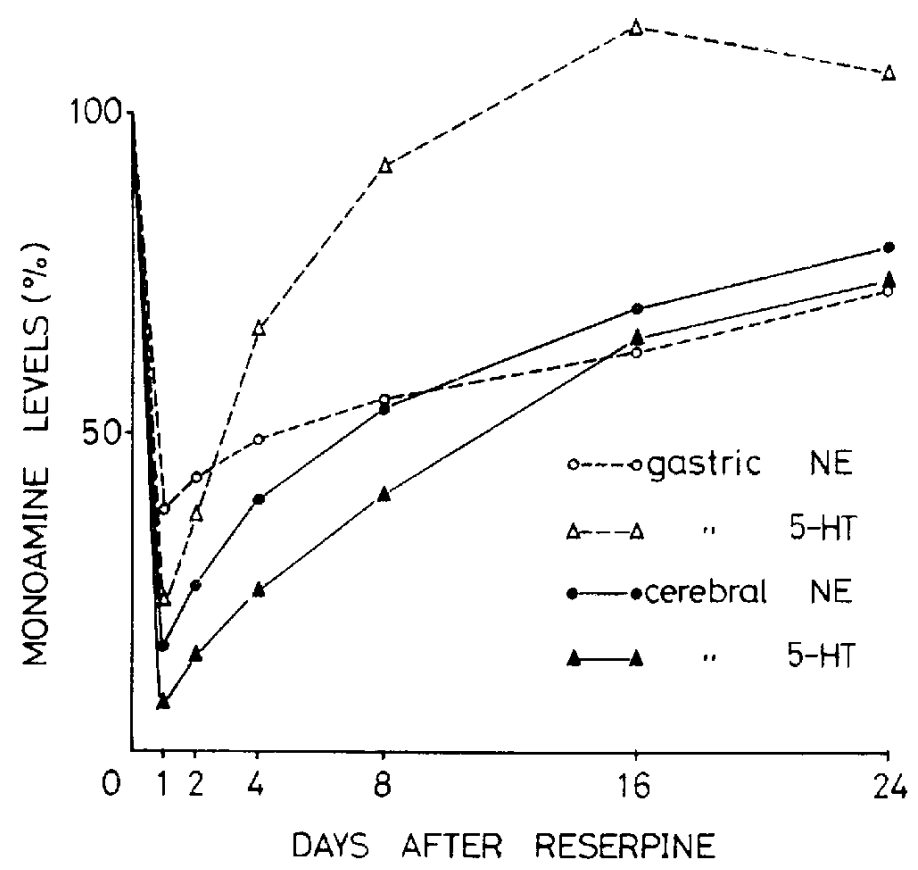

FIG. 4. Cerebral and gastric levels of norepinephrine and serotonin following reserpine $5 \mathrm{mg} / \mathrm{kg}$. Each point represents the mean value obtained with four animals, and is expressed as percent of control. 
4, 8, 16 and 24 days after reserpine (Fig. 4). In the figure, those levels in normal rats served as control values.

Both norepinephrine and serotonin levels in the brain were approx. $10 \%$ of the control $24 \mathrm{hr}$ after reserpine, thereafter recovering gradually. Twenty-four days after reserpine, both norepinephrine and serotonin levels in the brain were approx. $70 \%$ that of the control.

Both norepinephrine and serotonin levels in the stomach were reduced $20-40 \%$ that of the control, $24 \mathrm{hr}$ after reserpine, after which the levels of gastric norepinephrine recovered gradually, reaching approx. $70 \%$ of the control 24 days after reserpine. The scrotonin level in the stomach recovered more rapidly than did the gastric norepinephrine, cerebral norepinephrine and serotonin levels. After 8 days, the amount of gastric serotonin in reserpine treated rats was approx. the same as that in normal rats.

Time-course of the decrease in cerebral serotonin, norepinephrine and gastric norepinephrine was similar, and coincided well with the decrease in antisecretory activity of chlorpromazine and also with the increase of secretory volume after reserpine.

7. Effect of certain reserpine analogues and p-chlorophenylalanine on the monoamine levels, secretory volume and anisecretory activity of chlorpromazine in Shay rats

One $\mathrm{hr}$ after tetrabenazine ( $50 \mathrm{mg} / \mathrm{kg}$ s.c.), $24 \mathrm{hr}$ after reserpine ( $2.5 \mathrm{mg} / \mathrm{kg}$ s.c.), 24 hr after bietaserpine ( $10 \mathrm{mg} / \mathrm{kg}$ s.c.) and $48 \mathrm{hr}$ after p-chlorophenylalanine $(300 \mathrm{mg} / \mathrm{kg}$ i.p.), Shay rats were prepared in such a way that the antisecretory activity of chlorpromazine and the amount of norepinephrine and serotonin in the brain and the stomach could be determined.

Secretory volumes in Shay rats treated with reserpine, tetrabenazine, bietaserpine and p-chlorophenylalanine were $5.01 .0 .16,3.50 \perp 0.16,4.20\rfloor 0.32$ and $3.27 \ldots 0.30 \mathrm{ml}$ $100 \mathrm{~g}$ (mean $\perp$ S.E.), respectively. Significant difference $(p-0.05)$ from the corresponding control value, $3.63-0.24 \mathrm{ml} / 100 \mathrm{~g}$, was obscrved only in reserpine treated Shay rats.

The amount of norepincphrine and serotonin in the brain and the stomach after these drugs is demonstrated in Table 2. Decreases of norepinephrine and serotonin levels in the brain and the stomach due to these drugs were consistently observed but were varied in degree depending on the drugs. Reserpine was much more effective on the brain than on the stomach. The effect of tetrabenazine was approx. the same as that of reserpine.

TABLE 2. Effect of reserpine analogues and p-chlorophenylalanine on monoamine content.

\begin{tabular}{|c|c|c|c|c|c|c|}
\hline & & None & $\begin{array}{c}24 \mathrm{hr} \text { after } \\
\text { Reserpine } \\
2.5 \mathrm{mg} / \mathrm{kg} \mathrm{s.c.}\end{array}$ & $\begin{array}{l}24 \mathrm{hr} \text { after } \\
\text { Bictaserpine } \\
10 \mathrm{mg} / \mathrm{kg} \mathrm{s.c.}\end{array}$ & $\begin{array}{l}1 \mathrm{hr} \text { after } \\
\text { Tetrabenazine } \\
50 \mathrm{mg} / \mathrm{kg} \mathrm{s.t.}\end{array}$ & $\begin{array}{l}48 \text { hr after p-chlo- } \\
\text { rophenylalanine } \\
300 \mathrm{mg} / \mathrm{kg} \text { i.p. }\end{array}$ \\
\hline \multirow{2}{*}{ Brain } & NE & 0.42 & $0.11(26)$ & $0.28(67)$ & $0.14(33)$ & $0.39(93)$ \\
\hline & $5-\mathrm{HT}$ & 0.37 & $0.02(5.4)$ & $0.34(92)$ & $0.05(14)$ & $0.03(8.1)$ \\
\hline \multirow{2}{*}{ Stomach } & NE & 0.40 & $0.15 \quad(38)$ & $0.09(23)$ & $0.17(43)$ & $0.37(93)$ \\
\hline & $5-\mathrm{HT}$ & 1.27 & $0.69(54)$ & $1.50(118)$ & $1.42(112)$ & $0.67(53)$ \\
\hline
\end{tabular}

Monoamine contents are shown as microgram per gram of wet tissue and as percent of control in the parentheses. Each value is the mean of 4 animals. 
After reserpine and tetrabenazine, the brain level of norepinephrine was reduced to $20-30 \%$ of its initial value. while about a half of its initial content was still present in the stomach. On the contrary, after bietaserpine, the level of norepinephrine in the stomach was reduced $1020 \%$ of the initial value, while two-thirds of the initial content was determined in the brain. p-Chlorophenylalanine had hardly any effect on the levels of norepinephrine in the brain and the stomach.

The brain level of serotonin was markedly reduced by reserpine, tetrabenazine and p-chlorophenylalanine. Approx. $10 \%$ of the initial content of serotonin was determined. The brain Icvel of serotonin was hardly reduced by bietaserpine. The serotonin level in the stomach was reduced by reserpine and p-chlorophenylalanine to approx. $50 \%$ of the initial value, while no effect was seen with tetrabenazine and bietaserpine.

Injection of chlorpromazine did not induce any additional change in the brain and stomach monoamine levels in these animals.

The dose-response curve of antisecretory activity of chlorpromazine is shown in Fig. 5. After reserpine, the curve strongly shifted to the right. The antisecretory activity of chlorpromazine $8 \mathrm{mg} / \mathrm{kg}$ in rats injected with reserpine did not reach that of chlorpromazine $1 \mathrm{mg} / \mathrm{kg}$ in normal rats. A similar shift of dose-response curve was also observed after tetrabenazine.

Unlike reserpine and tetrabenazine, bietaserpine and p-chlorophenylalanine did not result in any change in the antisecretory activity of chlorpromazine.

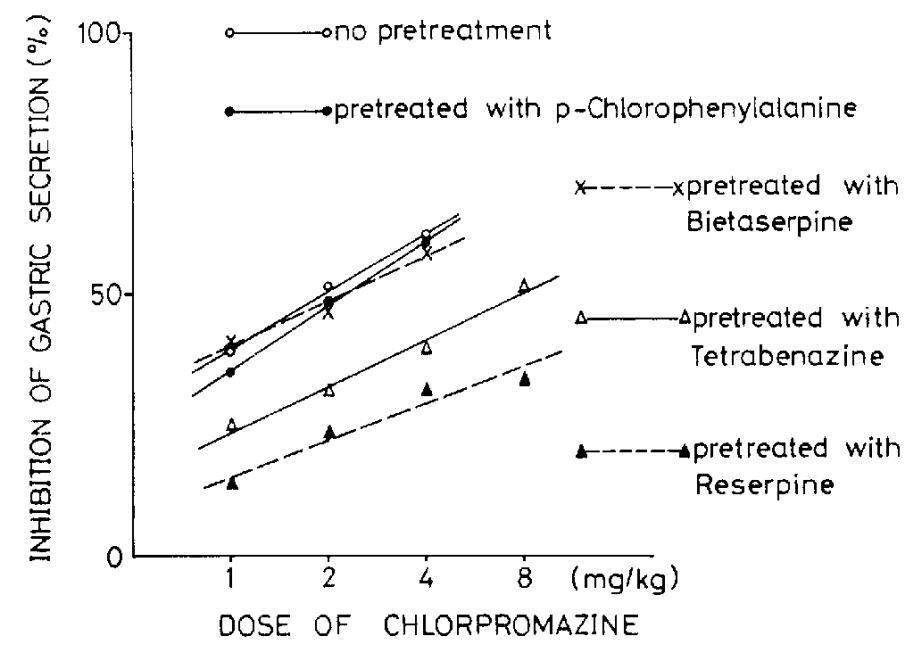

Fic. 5. Effect of reserpine analogues and p-chlorophenylalanine on antisecretory activity of chlorpromazine. Each point represents the mean of at least 10 animals.

\section{DISCUSSION}

When neuroleptics and antidepressants were studied regarding the inhibition of gastric secretion in Shay rats, the order of potency among the different drugs was: phenothiazines, butyrophenone, desipramine, amilriptyline and imipramine. These results are 
in agreement with those obtained by Bass and Patterson (4). The order of potency to prolong barbiturate sleep in mice was almost the same as that to inhibit gastric secretion in Shay rats. Anticholinergic activity of these drugs did not appear 10 be in this order (17).

As far as neuroleptics are concerned, the $100 \%$ prolonging dose of barbiturate sleep $\left(\mathrm{PD}_{100}\right)$ and the $50 \%$ inhibiting dose of gastric secretion in Shay rats $\left(\mathrm{ED}_{50}\right)$ exhibited a significant linear correlation. In addition, Sun and Shay (18) reported that chlorpromazine inhibited vagal gastric secretion rather by a central than by a peripheral (atropinelike) effect. Though changes in blood flow within the stomach may play a role in secretory inhibition (19), neuroleptics are known to be antagonistic to norepinephrine and serotonin which decrease blood flow and inhibit gastric secretion $(20,21)$. These results suggest a possible relationship between secretory inhibition and the central depression by neuroleptics. Komarov et al. (5) demonstrated that gastric secretory vol. was closely related to behavioral activity. This vol. was low in rats when the behavior index was low.

Desipramine was the most active antidepressant in inhibiting gastric secretion, but the anticholinergic action of desipramine was only half that of imipramine (17). The antisecretory potency of antidepressants appeared to be arranged in the order of potency to potentiate catecholamine. It is possible that the catecholamine potentiating action in the periphery is involved in the antisecretory action of antidepressants as suggested by Bass and Patterson (4).

In contrast to neuroleptjes and antidepressants, minor tranquilizers induced sedation without any reduction in gastric secretion. Different effects on brain neurochemical transmitters may be involved in this discrepancy between neuroleptics, antidepressants and minor tranquilizers. Neuroleptics and antidepressants are known to have many effects on catecholamines, but there is very little evidence suggesting interaction between benzodiazepine and catecholamines (22).

On the other hand, it is demonstrated that gastric secretion in Shay rats apparently increased after rescrpine, and returned to normal after 24 days. Time-course of the increase in gastric secretion was similar to that of the decrease in cerebral levels of norepinephrine and serotonin and the gastric level of norepinephrine. Bictaserpine was far weaker than reserpine in stimulating gastric secretion, although gastric norepinephrine was specifically depleted by the former. Tetrabenazine did not induce secretory enhancement, no doubt due to the rather short interval after administration. p-Chlorophenylalanine depleted the cerebral and gastric levels of serotonin to the same degree as did reserpine, but did not induce secretory stimulation. These results suggest that norepinephrine in the brain rather than in stomach plays a role in inhibiting gastric secretion. Emas (11) showed that sympathectomy or guanethidine treatment did not cause any change in basal secretion and secretagogue effect of reserpine in cats.

This report demonstrates, however, that the antisecretory action of neuroleptics and antidepressants observed in normal Shay rats was greatly diminished or abolished in Shay 
rats pretreated with reserpine $(5 \mathrm{mg} / \mathrm{kg}$ s.c.). These results confirm a previous assumption that the inhibitory effects of neuroleptics and antidepressants on gastric secretion are not due to an anticholinergic effect.

Atropine, pentolinium and bilateral vagotomy inhibited gastric secretion in reserpine treated Shay rats as well as in normal Shay rats. No significant difference was observed between these two preparations, the results of which suggest that vagal tone controls the gastric secretion in Shay rats treated with reserpine, as in normal Shay rats (3). The increased secretory volume in reserpine treated Shay rats appeared to be caused by the vagal enhancement which was derived from the depletion of central norcpincphrine, a possible inhibitory transmitter of the vagal tone. This speculation is supported by reports of other authors. Lee et al. (8) found that monoamines injected directly into the amygdala markedly depressed gastric responsiveness to the sacretagogues. More recently, Brodie et al. (23) reported that intracerebroventricular administration of clonidine, a central alphareceptor stimulant (24), inhibited gastric secretion in Shay rats. In addition, it has already been shown that the secretagogue effect of reserpine is abolished by pheniprazine (9), a monoamine oxidase inhibitor, or by repeated administration of reserpine (10).

The timc-course of decrease of antisecretory action of chlorpromazine coincided well with that of the decrease of cerebral levels of norepinephrine and serotonin and the gastric level of norepinephrine, but not with that of the gastric level of serotonin. Tetrabenazine also depleted both gastric and cerebral monoamines and reduced the antisecretory action of chlorpromazine. Antisecretory action of chlorpromazine was still however observed in Shay rats treated with bietaserpine or p-chlorophenylalanine. The results indicate that chlorpromazine cxhibits antisecretory action only when sufficient catecholamines are present in the brain. As chlorpromazine did not affect the content of endogenous norepinephrine in the brain (25), the interaction mechanism of chlorpromazine with catecholamines and the inhibition of gastric secretion was not clarified. Further studies are in progress.

Antidepressants were more effective than neuroleptics in inhibiting gastric secretion in reserpine treated rats. The antisecretory activity of desipramine was approx. that of chlorpromazine in normal Shay rats, and 3 times more active than that of chlorpromazine in reserpine treated rats. The potency ratio between normal Shay rats and reserpine treated Shay rats was almost the same among the different antidepressants.

The reduced antisecretory action of imipramine returned to normal more rapidly than that of chlorpromazine in reserpine treated Shay rats. The antisecretory action of imipramine was not closely related to monoamine levels in the brain or stomach. After rescrpine, however, nerve function recovered centrally (26) and peripherally (27) at a time when monoamine levels were still quite low. Antidepressants no doubt depress gastric secretion by potentiating catecholamine functioning in the brain or in the stomach. In this regard, it is interesting to note that it was the antidepressants not the neuroleptics which inhibited ulcer formation by reserpine (16). Doteuchi (28) has described the decrease in central monoamines to be involved in uker formation by reserpine and stress. 


\section{REFERENCES}

1) Shay, H., Komarov, S.A., Fel., S.S., Meranze, D., Gruenstein, M. and Siplet, H.: Gastroenterology 5, 43 (1945)

2) LeviNe, R.J.: Life Science 4, 959 (1965)

3) Brodie, D.A.: Am. J. Dig. Dis'. 11, 231 (1966)

4) Bass, P. And Patterson, M.A.: J. Pharmacol. exp. Ther. 156, 142 (1967)

5) Komarov, S.A., Bralow S.P., Shay, H. and Boyd, E.: Am. J. Physiol. 205, 230 (1963)

6) LfF, Y.H., Thompsov, J.H. ANd MCNew, J.J.: Am. J. Physiol. 217, 505 (1969)

7) Misher, A. ANd Brooks, F.P.: Am. J. Physiol. 211, 403 (1966)

8) Ridlfy, P.T. AND Brooks, F.P.: Am. J. Physiol. 209, 319 (1965)

9) Kim, K.S. Axid Srorf, P.A.: J. Pharmacol. exp. Ther. 141, 321 (1963)

10) Emàs, S.: Am. J. Dig. Dis. 13, 572 (1968)

11) EMÅs, S.: Acta physiol. scand. 60, 57 (1964)

12) Mead, A.A.R. And Finger, K.F.: Biochem. Pharmacol. 6, 52 (1961)

13) Shore, P.A. and Olis, J.S.: J. Pharmacol. exp. Ther. 122, 295 (1958)

14) Bogidanski, D.F., Pleisclier, A., Brodie, B.B. and Udenirilnd, S.: J. Pharmacol. exp. Ther. 117, 82 (1956)

15) Brodie, D.A. and Vatitski, L.S.: Proc. Soc. exp. Biol. Med. 113, 998 (1963)

16) Metršoví, J., Mety̌̌, J. and Votava, Z.: Int. J. Neuropharmacol. 3, 361 (1964)

17) Roor, W.S. And Hofmand, F.G.: Physiological Pharmacology, Vol. II, p. 234, Academic Press, New York (1965)

18) Sun, D.C.H. And Shay, H.: J. Pharmacol. exp. Ther. 126, 155 (1959)

19) Bynum, T.E. AND Jacobson, E.D.: Gastroenterology 60, 325 (1971)

20) Cowley, D.J. And Code, C.F.: Am. J. Physiol. 218, 270 (1970)

21) Winsilip, D.H. AND SHUCK, T.J.: Gastroenterology 58, 1008 (1970)

22) Valzfell, L.: Arch. int. Pharmacodyn. Thér. 196, 221 (1972)

23) Brodie, D.A., Lott, V.J. And BAufr, B.G.: Am. J. Dig. Dis. 15, 111 (1970)

24) Delbarre, B. and Schmitr, H.: European J. Pharmacol. 13, 356 (1971)

25) Gey, K.F. Anj Pletcher, A.: J. Pharmacol. exp. Ther. 133, 18 (1961)

26) HagGendal, J. AND LiNDQuist, M.: Acta physiol. scand. 57, 431 (1963)

27) Andín, N.-E. AND HeNivivg, M.: Acta physiol. scand. 67, 498 (1966)

28) Doteuchi, M.: Japan. J. Pharmacol. 18, 175 (1968) 